could be in place. Global carbon accounting, if it can be shown to work, would greatly reduce uncertainty about changes in atmospheric greenhouse-gas levels. And our understanding of climate sensitivity - the response of the climate to changing greenhousegas levels - is slowly improving (see, for example, J. M. Murphy et al. Nature 430, 768-772; 2004).

All this could strengthen the case for a Kyoto II agreement that would incorporate a target for the parameter of central importance in determining the course of climate change: the concentration of greenhouse gases in the atmosphere. A new agreement could have such a target at its core, advocates suggest. Such a deal would also include emissions targets, but would be flexible enough to allow changes in these secondary targets as more evidence comes to light, or if natural carbon cycles don't behave as expected.

At their summit meeting in March, European Union (EU) leaders announced a goal of keeping global temperature rise below $2{ }^{\circ} \mathrm{C}$ over pre-industrial levels. As temperatures have already increased by around $0.7^{\circ} \mathrm{C}$, this would limit future warming to $1.3^{\circ} \mathrm{C}$. The EU has also tentatively suggested that a $15-30 \%$ cut in greenhouse-gas emissions should be sought by 2020 .

But targets based on temperature or on emission ceilings still suffer credibility problems. With climate sensitivity still under debate, any given temperature target is necessarily associated with a broad range of possible emissions levels. Likewise, any emission target corresponds to a very wide range of temperature-change scenarios.

Focusing on greenhouse-gas concentrations could help policymakers steer clear of this uncertainty trap. An interim target of, say, 400 parts per million of carbon dioxide by 2030 might attract widespread political support. Given advances in global carbon accounting, it would also be more manageable and backed by more solid science than the other options. Such a target would have to be supported by goals for greenhousegas emissions, but these could be open to some modification in response to real-world observations and advances in scientific knowledge.

The Intergovernmental Panel

\section{"A Kyoto II agreement could incorporate a target for the concentration of greenhouse gases in the atmosphere."} on Climate Change (IPCC) - the scientific branch of the convention - is already compiling the latest advances in the science of climate change for its next assessment report, due in 2007. The challenge is to incorporate this knowledge into a viable, fair and effective new agreement.

Given the trenchantly negative approach of the current US administration (which will itself expire in 2008), it falls to the EU and developing countries to ensure that the Montreal meeting makes progress towards drafting a new agreement. Their negotiators, backed by the IPCC's findings and the climate-research community, must be decisive in translating the available scientific knowledge into a workable framework for the treaty that will succeed Kyoto.

\title{
Talent worth nurturing
}

\section{More should be done to draw people with disabilities into scientific careers.}

$\Lambda$ $s$ a News Feature in last week's Nature amply demonstrated, people with disabilities have a considerable array of talents to bring into science (see Nature 435, 552-554; 2005). But they face an array of obstacles in pursuing scientific careers. According to specialists in the field, the barriers start going up early on: many parents and schoolteachers are reluctant to press disabled children into subjects perceived to be challenging, such as science and mathematics. This is particularly unfortunate because these individuals may well have characteristics, such as problem-solving skills and perseverance, that would stand them in good stead in science.

Later on, the incentives and the equipment that could help individuals to function in the world of science are often lacking. In funding agencies and at universities, active support for the disabled as a group is sometimes patchy.

In the United States, the number of people with disabilities in higher education has tripled in the past 25 years, but they are still under-represented in science, technology, engineering and mathematics. According to the National Science Foundation (NSF), 7\% of people in these areas have some degree of disability, compared with $13 \%$ of the working population as a whole. Figures for the severely disabled are hard to find, but anecdotal evidence suggests that this group is badly under-represented in science.

Some noteworthy efforts exist to recruit, train and assist students with disabilities. The NSF's Research in Disabilities Education programme, for example, is spending $\$ 3$ million over five years to establishing 'regional alliances' to address the issue at a local level. The American Association for the Advancement of Science's Entry Point! programme collaborates with industry and government agencies to identify talented students and place them in paid summer internships. And NASA has recently established an initiative to help visually impaired students who would like to work there.

US institutions are legally obliged to make provision for the disabled under the landmark 1990 Americans with Disabilities Act. The European Union adopted a vaguer commitment to equal opportunities in 1996, but its application varies between nations. Mentoring of disabled scientists in Germany is encouraged, for example, by the Tandem Project at the Paul Ehrlich Institute in Frankfurt. In Britain, TechDis in York has prepared a host of valuable information for students with disabilities and their teachers. In addition, many colleges now include disability as a diversity issue, opening up funding opportunities previously allocated to women and ethnic minorities to people with disabilities.

Although laudable, these efforts are relatively small. Their limited scope contrasts with the extensive push that has been made to improve the opportunities for women and ethnic minorities in science. This is partly because the disabled are a smaller group, although not as small as you may think: there are an estimated 365,000 people with disabilities in science and engineering careers in the United States alone. But the more telling factor is the lack of direct political pressure on funding agencies to accommodate people with disabilities. That's a weak excuse for inaction in a sphere that cries out for some imaginative attention. 